\title{
Free Recall Trials 1-5
}

National Cancer Institute

\section{Source}

National Cancer Institute. Free Recall Trials 1-5. NCI Thesaurus. Code C120404.

The first part of the California Verbal Learning Test, second edition. For the first five trials, a 15-item list, List A, is read to the subject and he or she is asked to recall words from the list after each presentation. 